\title{
PERANCANGAN FONT TAPYCH BERBASIS KARAKTER VISUAL MOTIF KAIN TAPIS LAMPUNG
}

\author{
Wantoro $^{1}$, Kankan Kasmana ${ }^{2}$ \\ ${ }^{1,2}$ Program Studi Desain Komunikasi Visual, Universitas Komputer Indonesia, Bandung. \\ 1 amwantoro@yahoo.com, ${ }^{2}$ melihat2@yahoo.com
}

\begin{abstract}
Abstrak
Tapis merupakan kain khas asal Lampung yang terbuat dari tenunan benang kapas berwarna emas dan perak. Sebagai produk budaya, tapis memiliki visualisasi yang khas. Berdasarkan observasi, pemanfaatan tapis yang memiliki representasi nilai dan nilai estetika tinggi masih terbatas pada media dan waktu tertentu. Hal ini tentu saja menimbulkan kekhawatiran tentang pelestarian dan pengembangan tapis karena keterbatasan pemanfaatannya. Contoh pemanfaatan tapis yang dapat dilakukan adalah upaya eksplorasi visual kedalam bentuk produk budaya lain yang lekat dengan keseharian masyarakat. Salah satu produk budaya yang dapat dirancang adalah huruf. Huruf merupakan media komunikasi tulisan yang sebenarnya telah lama ada dan berkembang. Di Indonesia, komunikasi tulisan mayoritas menggunakan huruf latin. Penggunaan huruf latin di Indonesia dapat dilihat mulai dari cara manual hingga sudah dilakukan secara digital. Huruf digital atau disebut dengan font saat ini banyak digunakan pada perangkat-perangkat digital/elektronik. Perkembangan desain font juga terus berkembang karena kebutuhan akan penyampaian pesan maupun kesan estetis pada suatu karya juga berkembang. Hal inilah yang kemudian menginspirasi lahirnya kemungkinankemungkinan bentuk visual baru font khususnya yang berbasis huruf Latin. Tapis, dengan kekayaan estetik pada visualnya dapat dijadikan sebagai inspirasi dalam menciptakan kemungkinan bentuk baru dari sebuah font yang berbasis pada bentuk huruf latin. Perpaduan visual antara tapis dan karakter huruf latin dapat menghasilkan karakteristik yang khas.
\end{abstract}

Kata Kunci: Adaptasi, Font, Perancangan, Tapis, Visual.

\begin{abstract}
Tapis from Lampung is a unique fabric made from cotton yarn woven gold and silver. As cultural products, Tapis have a typical visualization. Based on observations, the use of Tapis which has a value of representation and a high aesthetic value is still limited to the media and a certain time. This raises concerns about the preservation and development of the Tapis due to the limited utilization. Examples of the use of Tapis that can be done is a visual exploration efforts into other forms of cultural products attached to everyday people. A cultural product that can be designed is the letter. Letter is a medium of communication that has long been there and growing. In Indonesia, the majority of written communications using Latin letters. The use of the Latin alphabet in Indonesia can be seen from how the user until it is done digitally. Digital letter or called by the current font is widely used in digital devices / electronic. Font design development is also growing because of the need for the delivery of messages as well as the growth of aesthetic impression. This inspired the birth of the possibilities of new visual font forms especially based Latin letters. Tapis, with the wealth of the visual aesthetic can be used as inspiration in creating the possibility of a new font form based. Visual fusion between Tapi and the Latin alphabet characters can produce distinct characteristics.
\end{abstract}

Keywords: Adaptation, Fonts, Design, Tapis, Visual. 


\section{PENDAHULUAN}

\subsection{Latar Belakang}

Salah satu kekayaan budaya visual yang dimiliki Indonesia adalah kain Tapis yang berasal dari Lampung. Kain Tapis memiliki visualisasi yang khas yang merujuk pada alam, flora, fauna dan kehidupan masyarakat Lampung. Potensi kain Tapis yang memiliki representasi nilai dan nilai estetika tinggi seyogyanya dapat dimanfaatkan dan dikembangkan kedalam bentuk produk budaya yang lain. Hal ini perlu dilakukan sebagai upaya inovatif dalam pelestarian dan pemaksimalan fungsi pemanfaatan kain Tapis.

Salah satu bentuk pemanfaatan dan pengembangan Tapis yang dapat dilakukan adalah upaya eksplorasi visual kedalam huruf. Huruf adalah salah satu elemen grafis yang penting untuk melengkapi suatu rancangan desain yang dipresentasikan kepada khalayak luas. Merujuk pada Sihombing, tipografi sebagai ilmu dalam menyusun huruf yang tepat dalam desain mampu menerjemahkan apa yang ingin disampaikan sehingga terbentuklah korelasi antara fungsi dan estetika [1]. Perkembangan huruf di Indonesia sebenarnya telah ditunjukkan dengan banyaknya aksara lokal dari berbagai suku bangsa yang ada. Aksara-aksara tersebut memiliki ciri-ciri serta karakteristik tersendiri yang ditandai dengan bentuk, gaya, dan kesan. Namun, meskipun Indonesia memiliki banyak aksara lokal namun dalam kenyataannya cara berkomunikasi tulisan di Indonesia mayoritas menggunakan huruf Latin. Huruf latin yang kini telah banyak dibuat dalam bentuk file digital atau disebut dengan font banyak digunakan pada perangkat komputer, gadget atau perangkat elektronik lainnya karena kemudahan penggunaan. Dengan pendekatan dari karakter visual pada kain Tapis, maka yang dilakukan adalah dengan merujuk pada satu bentuk dan merepresentasikan identitas hasil inovasi pada bentuk font yang mengacu pada pakem bentuk huruf latin yang telah terbiasa digunakan masyarakat. Berdasarkan uraian sebelumnya, huruf latin dipilih untuk kemudian dikembangkan menjadi font karena jenis huruf tersebut telah terbiasa dan umum digunakan banyak masyarakat.

Berdasarkan fenomena diatas, eksplorasi tipografi (font) yang terinspirasi dari karakter visual Tapis, selain akan menciptakan kemungkinan visual baru untuk huruf latin juga memudahkan pengenalan dan pengembangan Tapis itu sendiri.

\subsection{Font}

Kata font sendiri berasal dari bahasa Perancis yaitu Fonte. Font merupakan file berekstensi TTF (True Type Font) atau OTF (Open Type Font) yang didalamnya berisi digitalisasi huruf, angka, simbol, tanda baca dan lainnya yang dirancang dengan perangkat atau software khusus seperti FontLab Studio, Glyph atau FontCreator. Pada awalnya, istilah font sendiri digunakan untuk penamaan satu set metal type dari suatu typeface yang sama ukuran dan style-nya [2]. Saat ini, font digunakan pada perangkat digital seperti PC (Personal Computer), Laptop, Gadget, dan sebagainya. Contoh Font yang populer saat ini antaralain Arial.ttf, Calibri.ttf, Helvetica.ttf, Times New Roman.ttf dan lain sebagainya. Para perancang font sering disebut sebagai font designer. Para font designer biasanya bekerja secara individu atau bekerja untuk sebuah perusahaan font yang disebut sebagai type foundry. 


\subsection{Kain Tapis}

Menurut Dinata, kain Tapis merupakan pakaian adat suku Lampung yang terbuat dari tenunan benang kapas berwarna emas dan perak dengan sistem sulam (dalam bahasa Lampung disebut dengan "cucuk") dan menghasilkan motif-motif yang beragam dan merujuk pada referensi dari alam, flora, dan fauna [3]. Jenis motif kain Tapis yang dipilih sebagai referensi visual dalam perancangan ini adalah kain Tapis dengan motif kapal. Motif kapal merupakan salah satu motif kain Tapis yang banyak digunakan. Motif ini merupakan produk percampuran budaya yang dilakukan oleh masyarakat Animisme, Dinamisme, Hindu, Budha hingga Islam [4]. Motif kapal dipilih memiliki karakter yang khas.

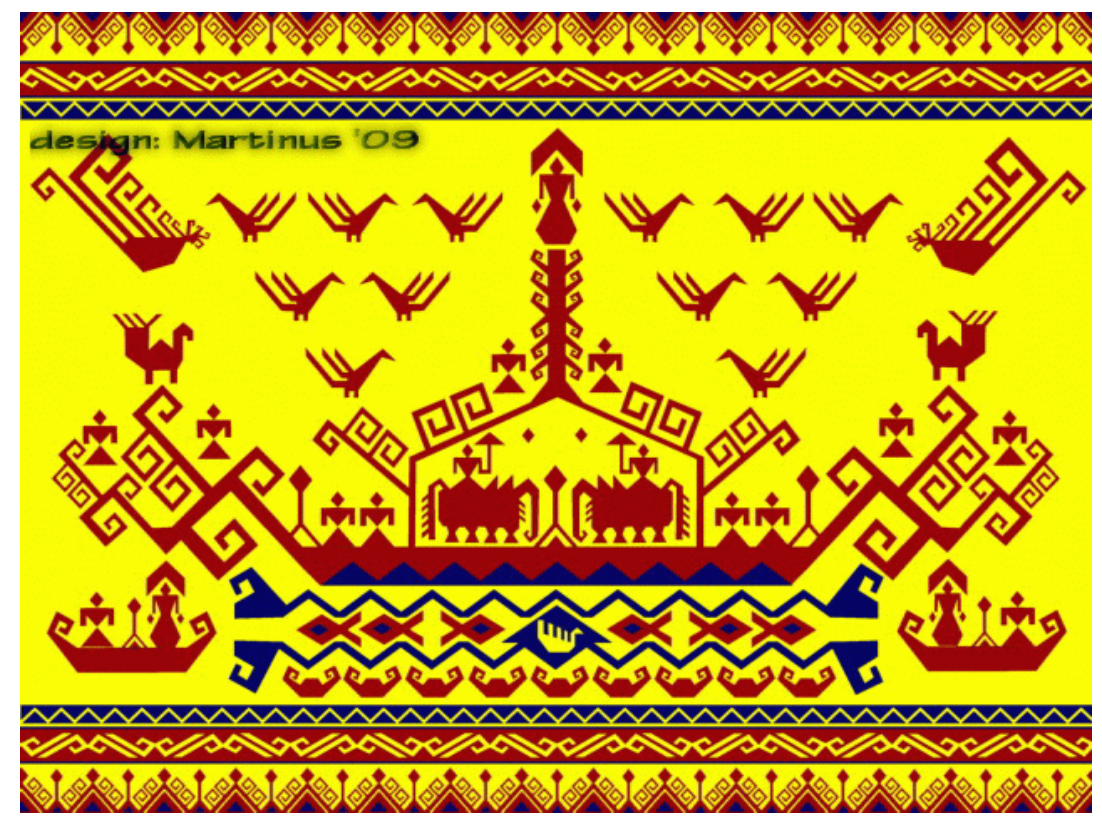

Gambar 1. Contoh Tapis Lampung Motif Kapal

[Sumber : https://kainkapal.files.wordpress.com/2009/10/kapal20web1.gif Diakses pada : 29 Oktober 2016]

\section{METODE PENELITIAN}

\subsection{Metode Pengumpulan Data}

Dalam pengumpulan data, beberapa metode yang digunakan antaralain :

a. Studi Literatur

Studi ini merupakan metode dengan mempelajari literatur seperti buku, jurnal, penelitian, majalah dan sebagainya berkaitan dengan kain Tapis dan tipografi (huruf/font). Hasil yang didapat dijadikan sebagai teori dan dasar dalam perancangan font berbasis karakter visual kain Tapis.

b. Observasi

Metode observasi dilakukan dengan cara melakukan pengamatan secara langsung, baik pada obyek sumber maupun contoh hasil akhir font lain dan melakukan pencatatan hal-hal penting guna mengumpulkan temuan baru di lapangan yang berkaitan dengan perancangan. 


\subsection{Metode Perancangan Huruf}

Wilayah penelitian dan perancangan dalam konteks ini adalah identitas budaya lokal dengan studi kasus kain Tapis yang berasal dari Lampung. Eksplorasi visual Tapis Lampung kemudian akan menjadi sebuah font lengkap yang terdiri dari 26 huruf kapital (UPPERCASE), 26 huruf kecil (lowercase), angka, tanda baca dan simbol. Keseluruhan proses tersebut akan diterjemahkan sebagai sistem perancangan. Font yang dirancang secara garis besar masih akan memiliki kegunaan utama yakni sebagai alat baca yang mempertimbangkan aspek keterbacaan (readibility) dan kejelasan (legible) disamping secara estetis mampu menunjukkan keunikan dari identitas dari objek yang telah diambil. Secara umum, metode dan tahapan dalam perancangan font berbasis visual kain Tapis yaitu :
a. Menentukan brief
b. Menentukan ide/inspirasi utama
c. Menentukan Keywords
d. Menentukan Keyvisual
e. Menentukan arahan desain huruf
f. Membuat sketsa desain huruf
g. Digitalisasi Vector
h. Import file Vector ke FontLab Studio
i. Pengaturan Font di FontLab Studio
j. $\quad$ Instalasi Font menjadi TTF (True Type Fonts)

\section{HASIL DAN PEMBAHASAN}

\subsection{Proses Perancangan Font}

Pada perancangan ini, penulis menggunakan perangkat-perangkat desain (hardware ataupun software) antaralain seperti Adobe Illustrator Creative Cloud (CC) dan FontLab Studio versi 5.2. Software Adobe Illustrator CC digunakan untuk men-tracing sketsa yang digunakan dengan basis vector desain font. FontLab Studio versi 5.2 digunakan untuk mendigitalisasikan huruf menjadi font. Software lain yang digunakan adalah Adobe Photoshop CS6 untuk pembuatan poster font.

Beberapa keywords yang dapat disimpulkan dari kain Tapis adalah sebagai berikut bentuk ulir yang tegas, kaku dan sederhana. Keywords tersebut jika ditransformasikan ke keyvisual adalah sebagai berikut :

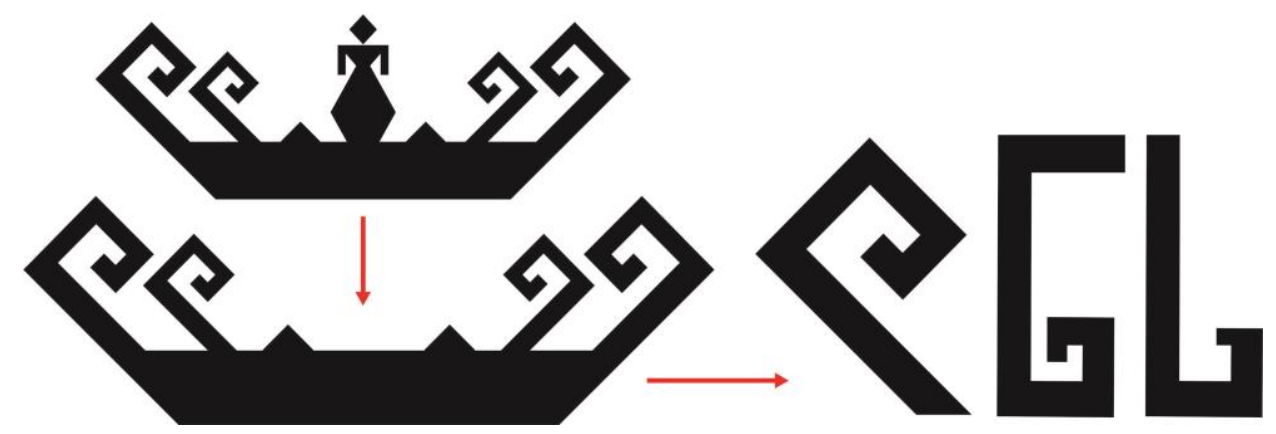

Gambar 2. Keyvisual

[Sumber : Wantoro \& Kankan, 2016] 
Keyvisual diatas merupakan adaptasi dan penyederhanaan dari ujung bentuk motif kapal dan menurut penulis cukup representatif dan dapat dijadikan inspirasi visual pada huruf, khususnya pada bagian tangkai (stem/kait). Sehingga, perancangan huruf akan diarahkan pada hasil sebagai huruf serif.

Setelah keyvisual ditentukan, tahap selanjutnya adalah mewujudkan gagasan visual kedalam bentuk sketsa manual. Proses diawali dengan membuat sketsa untuk rancangan huruf UPPERCASE atau kapital di kertas milimeter blok. Huruf UPPERCASE didesain dengan ketinggian yang sama. Setiap huruf memiliki serif (kait) yang terinspirasi dari keyvisual motif kapal pada kain Tapis Lampung.

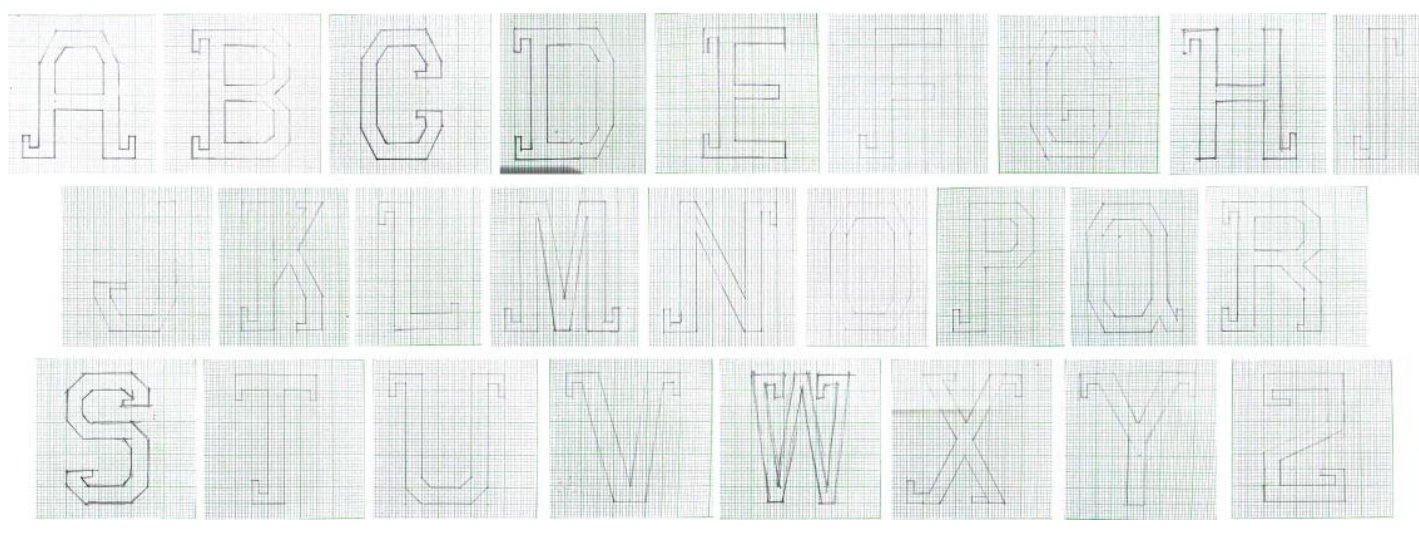

Gambar 3. Sketsa Huruf UPPERCASE

[Sumber : Wantoro \& Kankan, 2016]

Setelah menyelesaikan 26 karakter huruf UPPERCASE, langkah selanjutnya adalah merancang sketsa manual huruf lowercase atau kecil.

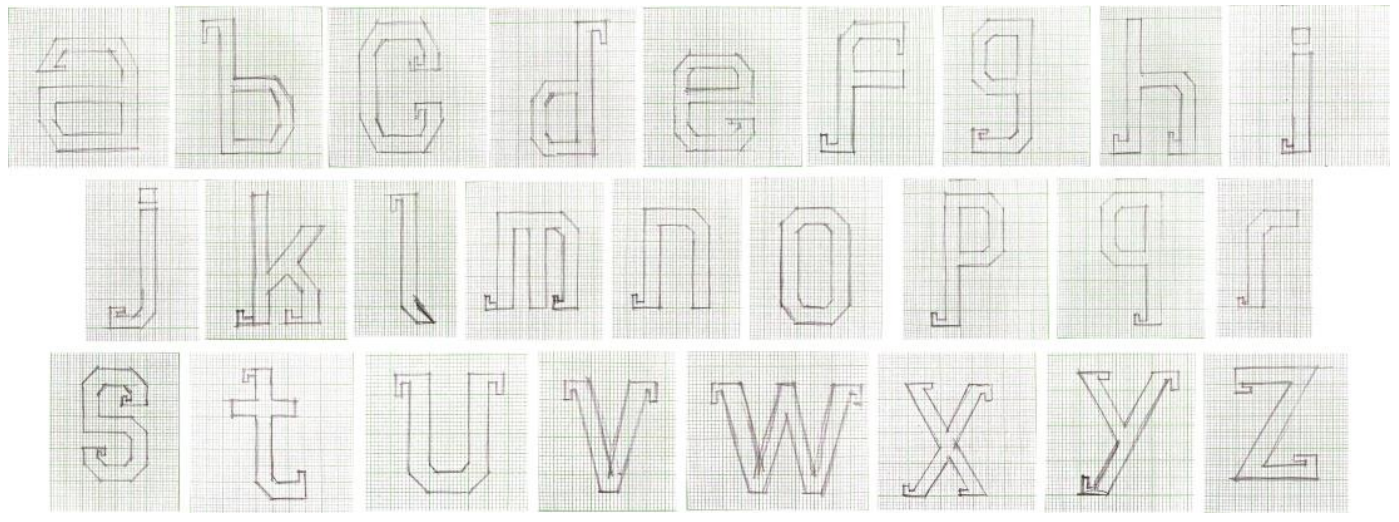

Gambar 4. Sketsa Huruf lowercase

[Sumber : Wantoro \& Kankan, 2016]

Proses sketsa selanjutnya adalah membuat angka dan tanda baca. Angka terdiri atas $0,1,2,3,4,5,6,7,8$ dan 9. Sementara tanda baca yang dibuat yaitu ’!@\#\$\%^\&*()_$+=\{\}[] \mid \backslash: ;<>$, ? $/$ 
Setelah sketsa huruf lengkap, maka sketsa discan/pindai mengggunakan scanner Epson Lide110. Hasil scan/pindai kemudian di-tracing (jiplak untuk digambar ulang menggunakan tool pencil/pen) menggunakan software Adobe Illustrator Creative Cloud (CC) agar menghasilkan gambar digital berbasis vector. Proses tracing, juga sama dengan langkah sketsa yaitu huruf UPPERCASE dikerjakan terlebih dahulu.

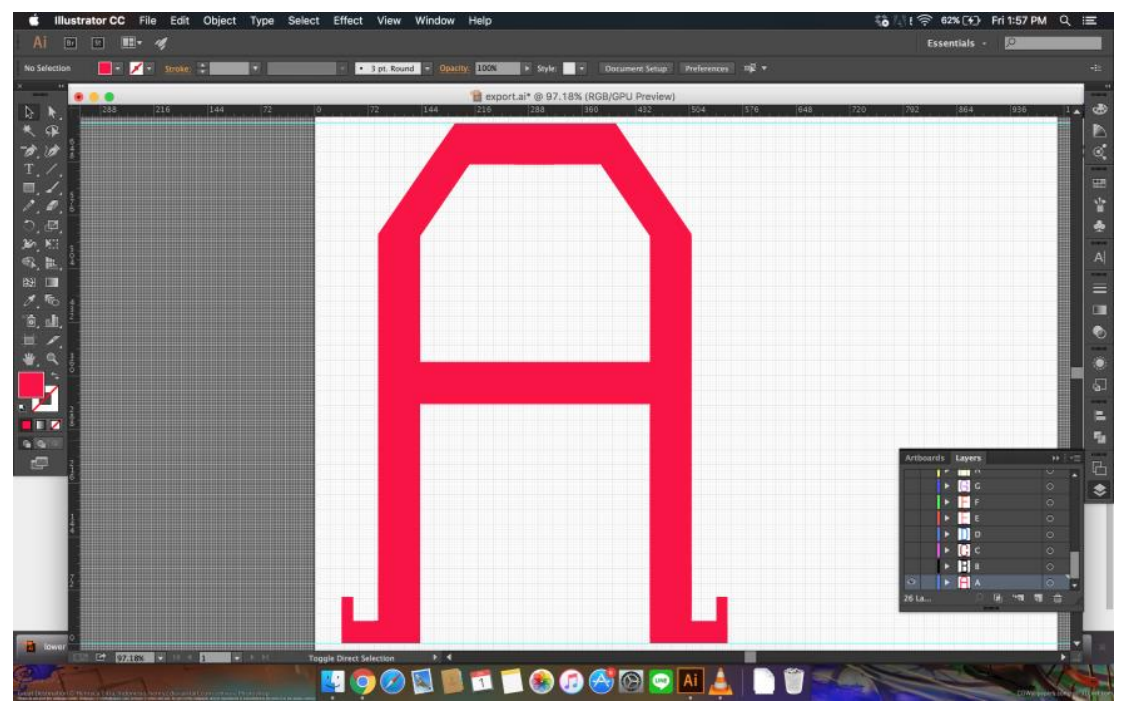

Gambar 5. Digitalisasi huruf "A" UPPERCASE di Adobe Illustrator CC

[Sumber : Wantoro \& Kankan, 2016]

Setelah proses tracing huruf-huruf UPPERCASE selesai, maka proses dilanjutkan ke huruf lowercase (kecil). Seperti halnya huruf UPPERCASE, pada huruf lowercase penggunaan fasilitas ruler juga sangat membantu agar proses tracing. Setelah menyelesaikan proses tracing pada kelompok huruf, baik UPPERCASE maupun lowercase maka proses dilanjutkan dengan tracing kelompok angka dan tanda baca.

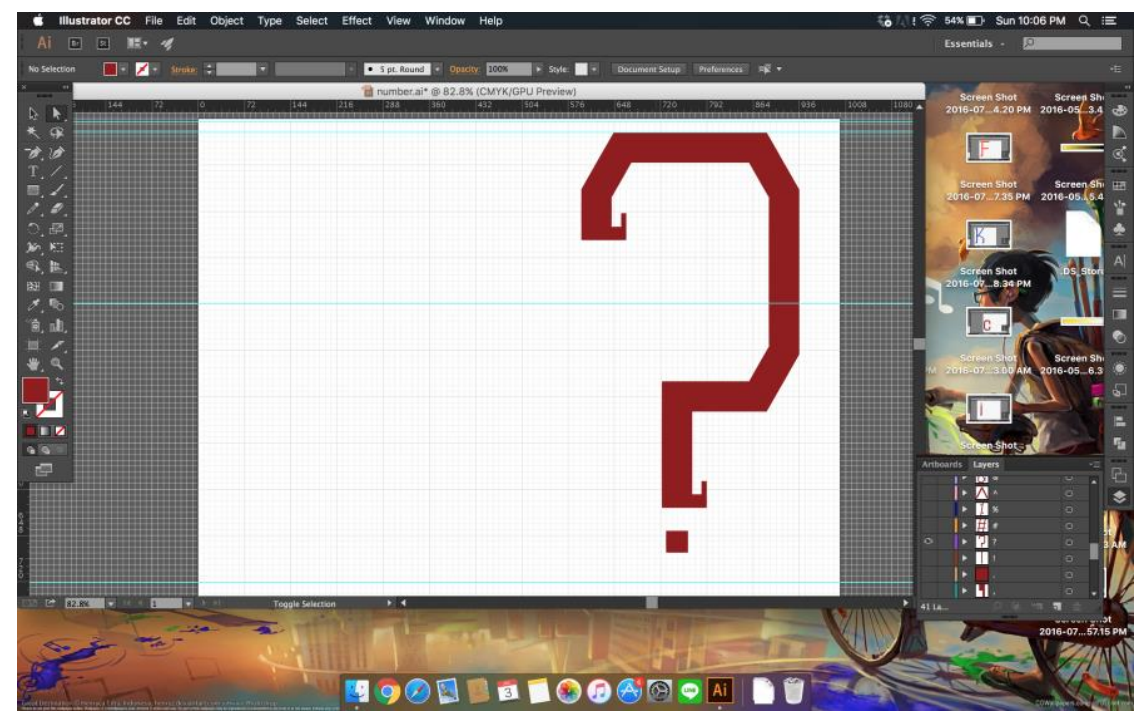

Gambar 6. Digitalisasi tanda baca di Adobe Illustrator CC

[Sumber : Wantoro \& Kankan, 2016] 
Beberapa tanda baca memiliki kesamaan bentuk. Seperti contoh tanda baca " $\{$ " dan " $\}$ " memiliki kesamaan namun hanya arah yang berbeda. Untuk mengefektifkan proses dan menciptakan presisi huruf maka langkah yang dilakukan hanya perlu menduplikat dan membalik (flip) salah satu tanda baca.

Untuk menjadikan huruf digital sebagai font, perlu langkah lanjutan yang dilakukan. Hasil digitalisasi huruf yang telah selesai di Adobe Illustrator Creative Cloud (CC) kemudian dimasukkan/copy ke software pembuat font. Dalam perancangan ini digunakan software FontLab Studio versi 5.2 yang merupakan versi terakhir dari seri software tersebut.

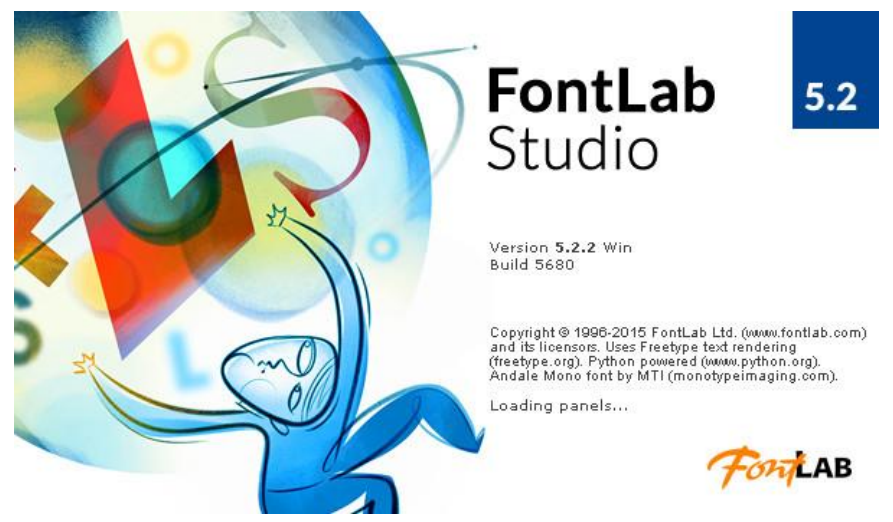

Gambar 7. Tampilan Awal Fontlab Studio 5.2

[Sumber : Wantoro \& Kankan, 2016]

Setelah mengimpor semua karakter baik huruf, angka maupun tanda baca, perlu untuk memeriksa detail semua karakter huruf. Hal ini dilakukan untuk mengetahui kerapihan dan detail huruf. Untuk melakukannya, dapat menggunakan fasilitas zoom in (Z) dengan menggunakan ikon kaca pembesar dan navigasi keliling menggunakan spacebar.

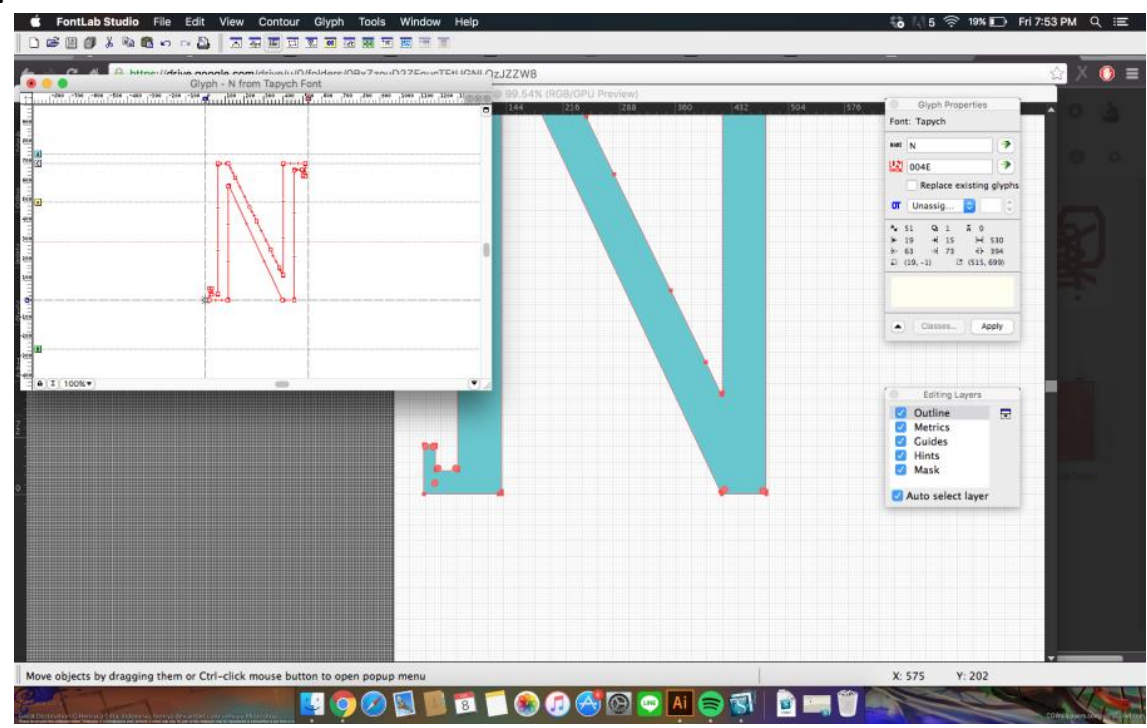

Gambar 8. Glyph Window huruf "N" UPPERCASE di FontLab Studio versi 5.2 [Sumber : Wantoro \& Kankan, 2016] 
Setelah melalui proses finalisasi desain font di FontLab Studio, font siap diinstal dengan cara Generate Font dan disimpan dalam format OpenType PS seperti tampak dibawah.

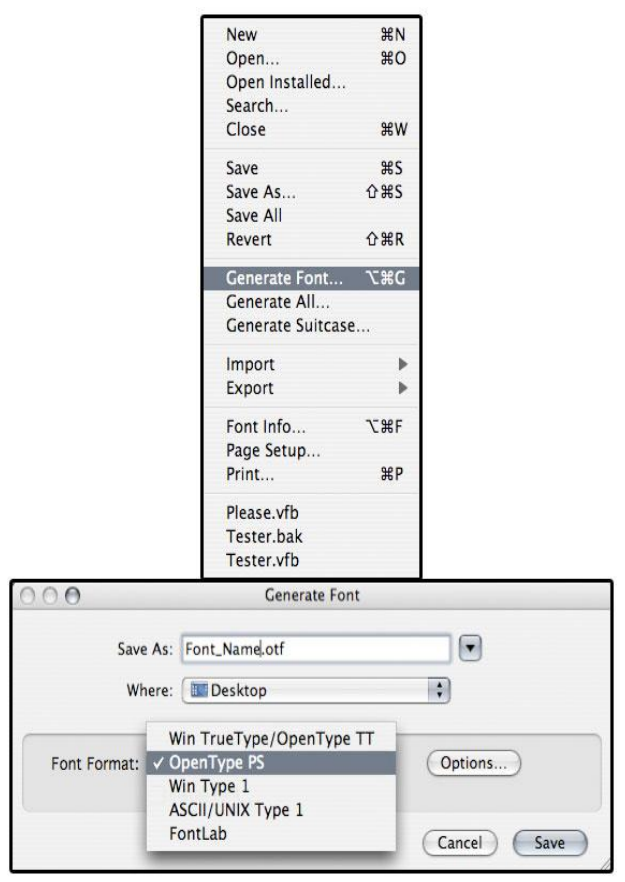

Gambar 9. Generate Font

[Sumber : Wantoro \& Kankan, 2016]

\subsection{Hasil Font}

Setelah melalui serangkaian proses di atas, font yang telah selesai kemudian disimpan dan diberi nama Tapych. Nama Tapych terinspirasi dan merupakan "plesetan" dari nama Tapis. Adapun rincian font Tapych adalah sebagai berikut :

a. Huruf UPPERCASE

Font Tapych terdiri dari 26 huruf UPPERCASE atau kapital yaitu $A, B, C, D, E, F, G$, $\mathrm{H}, \mathrm{I}, \mathrm{J}, \mathrm{K}, \mathrm{L}, \mathrm{M}, \mathrm{N}, \mathrm{O}, \mathrm{P}, \mathrm{Q}, \mathrm{S}, \mathrm{T}, \mathrm{U}, \mathrm{V}, \mathrm{W}, \mathrm{X}, \mathrm{Y}$, dan Z.
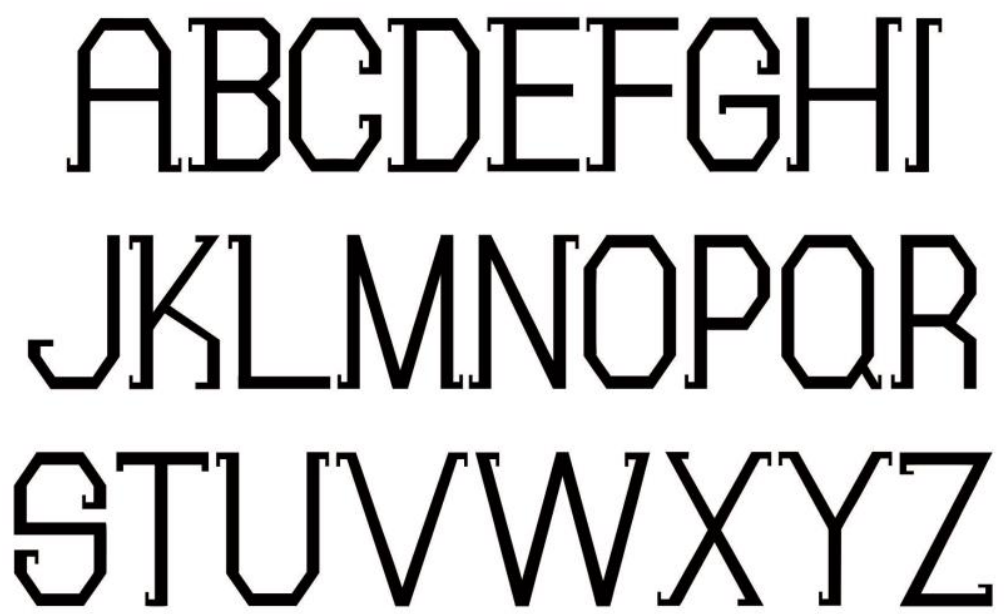

Gambar 10. Hasil Akhir Font Tapych untuk Huruf Kapital (uppercase) [Sumber : Wantoro \& Kankan, 2016] 


\section{b. Huruf lowercase}

Font Tapych terdiri dari 26 huruf lowercase atau kecil yaitu a, b, c, d, e, f, g, h, i, j, $k, l, m, n, o, p, q, s, t, u, v, w, x, y$, dan $z$.

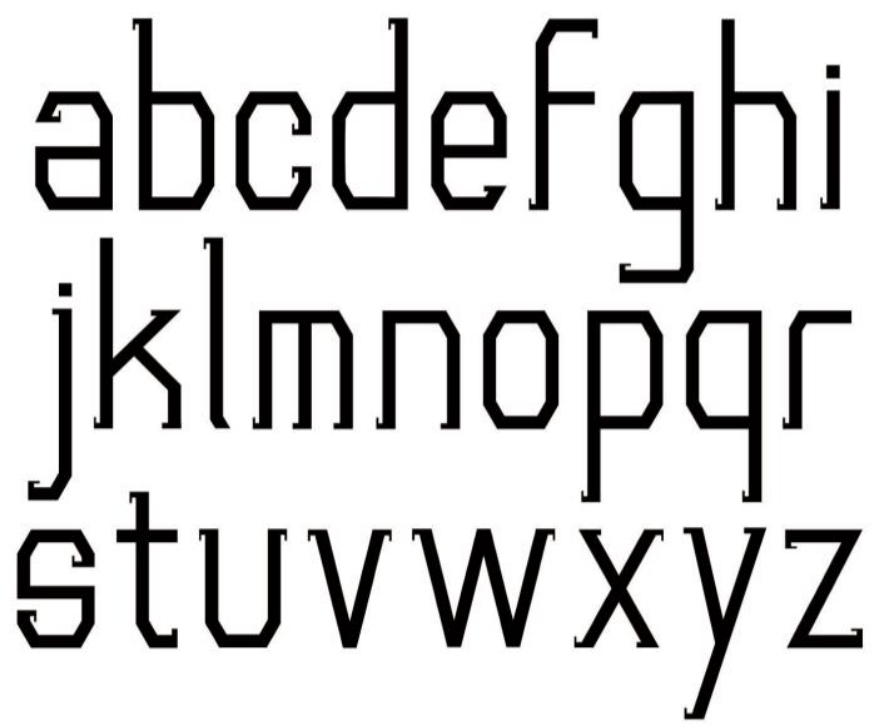

Gambar 11. Hasil Akhir Font Tapych untuk Huruf Kecil (lowercase) [Sumber : Wantoro \& Kankan, 2016]

c. Angka

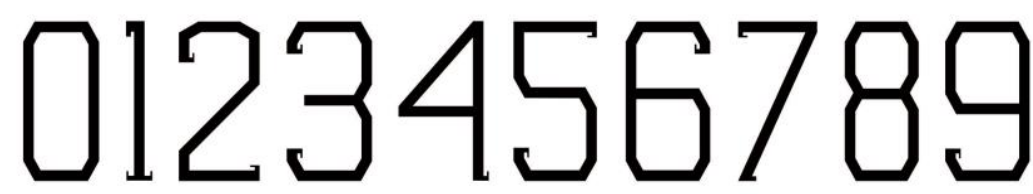

Gambar 12. Hasil Akhir Font Tapych untuk Angka

[Sumber : Wantoro \& Kankan, 2016]

d. Tanda Baca
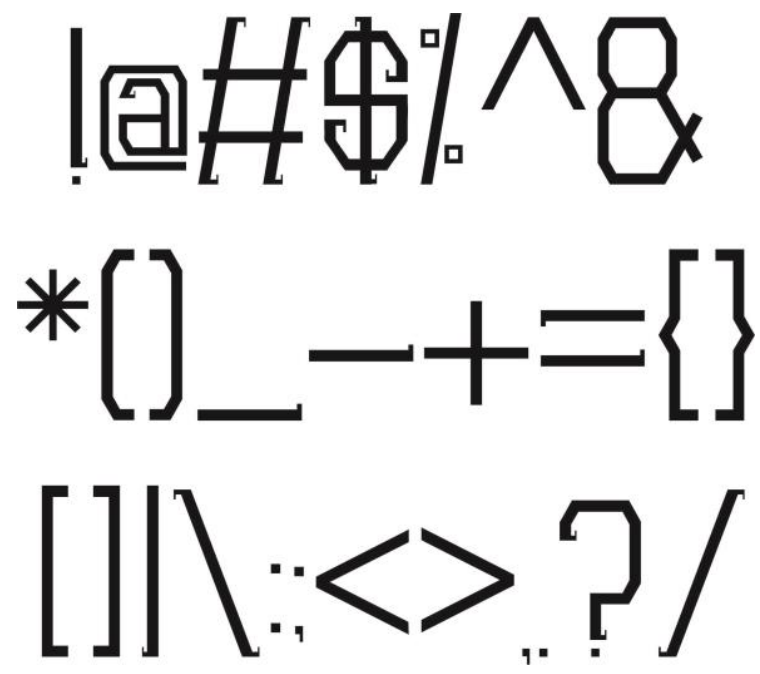

Gambar 13. Hasil Akhir Font Tapych untuk Tanda Baca [Sumber : Wantoro \& Kankan, 2016] 
Font yang telah selesai kemudian disimpan dalam ekstensi TTF (True Type Font). dan diberi nama Tapych.

\begin{tabular}{|c|}
\hline 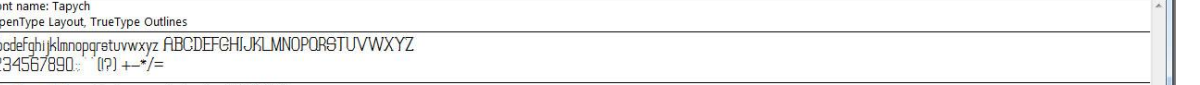 \\
\hline 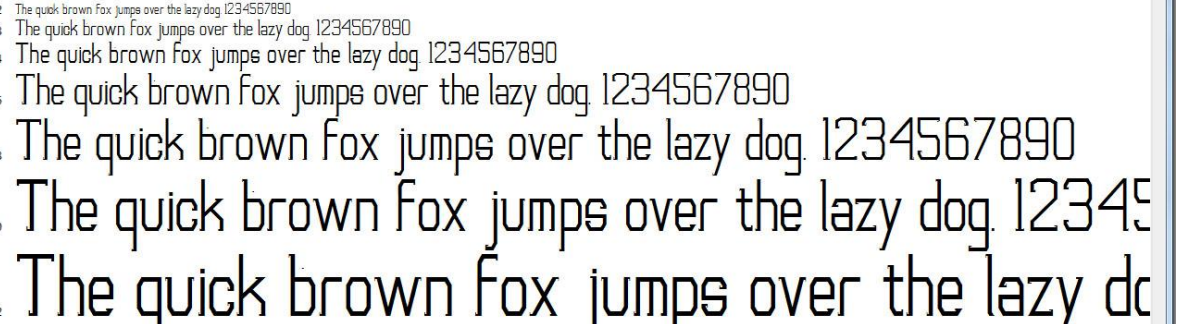 \\
\hline
\end{tabular}

Gambar 14. Hasil akhir Font dilihat dari Preview

[Sumber : Wantoro \& Kankan, 2016]

Font yang telah selesai dibuat, diaplikasikan dalam media cetak. Media cetak yang dipilih adalah poster. Pengaplikasian dilakukan guna mengetahui seberapa efektif dan estetis suatu font dalam sebuah media. Didalam poster, font Tapych akan dikombinasikan dengan warna merah kuning mengacu pada warna dominan Tapis Lampung, ilustrasi motif kapal, dan elemen grafis sebagai estetika.

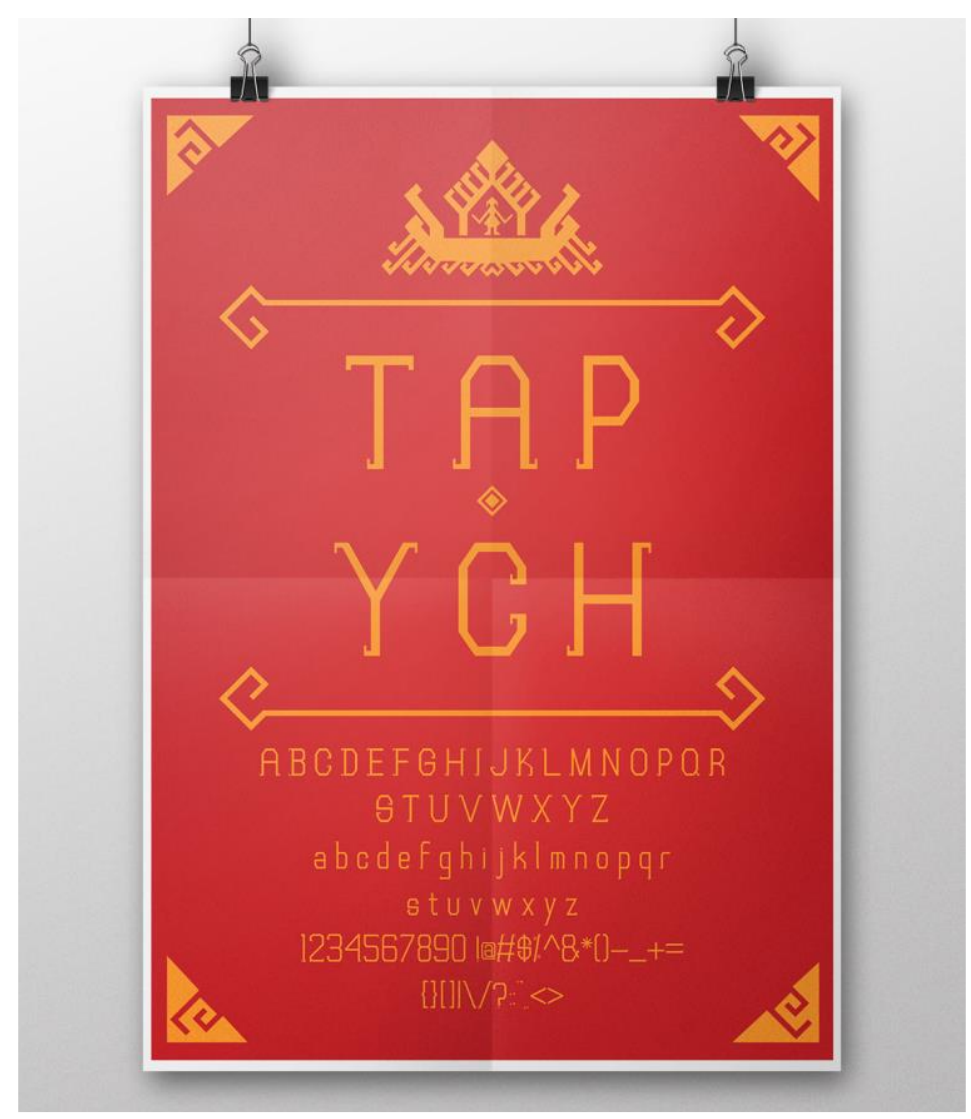

Gambar 15. Contoh aplikasi Font dalam bentuk Poster [Sumber : Wantoro \& Kankan, 2016] 


\section{KESIMPULAN}

\subsection{Kesimpulan}

Berdasarkan penelitian dan perancangan yang telah penulis lakukan, maka kesimpulan yang dapat ditarik yaitu Tapis, sebagai produk budaya Indonesia memiliki potensi tinggi secara visual yang dapat menginspirasi penciptaan-penciptaan karya baru seperti desain font. Hal ini juga sebagai langkah inovatif guna melestarikan dan mengembangkan produk budaya seperti Tapis Lampung melalui font.

\subsection{Saran}

Di dalam perancangan font yang berlandaskan pada eksplorasi visual objek budaya seperti kain Tapis, beberapa hal yang harus diperhatikan yaitu penting bagi perancang font untuk tetap memperhatikan karakteristik khas sebuah obyek yang akan dijadikan sebagai referensi sehingga desain pengembangan font yang dihasilkan tidak meninggalkan kekhasan visual. Selain itu, dalam penciptaan font, penting untuk menentukkan tujuan yang ingin dicapai. Jika ingin menghasilkan font untuk keperluan teks, maka bentuk huruf harus memiliki tingkat readibility dan legibility yang baik yang tersusun melalui stroke huruf dan sebagainya.

\section{DAFTAR PUSTAKA}

[1] Sihombing, Danton. (2003). Tipografi dalam Desain Grafis. Jakarta: PT. Gramedia Pustaka Utama.

[2] Rustan, Surianto. (2011). Hurufontipografi. Jakarta: PT. Gramedia Pustaka Utama.

[3] Dinata AR, Artha. (2008). Kain Tapis Lampung. Dikutip dari https://arthaliwa.wordpress.com/2008/12/14/kain-tapis-lampung/ (Diakses 26/04/2015).

[4] Ramadhan, Bagus. (2015). Keindahan Kain Tenun Tapis dari Lampung. Dikutip dari https://www.goodnewsfromindonesia.org/2015/09/09/keindahan-kaintenun-tapis-dari-lampung (Diakses 05/08/2016) 